\title{
Solving Octagonal Fuzzy Sequencing Problem using New Ranking Method
}

\author{
Althada Ramesh Babu, B Rama Bhupal Reddy
}

\begin{abstract}
In this paper, a new method is proposed for solving octagonal fuzzy sequencing problem using new ranking method (taking $k=0.5$ ) for converting crisp problem for finding Job sequence of two machine $n$ jobs. The optimality for the completion of the task and idle time for each machine is obtained by solving corresponding sequencing problem using Johnsons's rule. It is illustrated with a numerical example.
\end{abstract}

Index Terms: Octagonal Fuzzy Number, Fuzzy sequencing problem, Fuzzy Optimal sequencing, Octagonal fuzzy membership function, New Ranking method \& Johnson's rule.

\section{INTRODUCTION}

Since the development of fuzzy set by Zadeh [3] in 1965, there have been many research studies applying it in various domains. It was applied in decision making process by Bellman and Zadeh [1]. Fuzzy environment has been applied in the domain of engineering applications, for solving linear programming problems techniques as stated in Fang. S.C[2]. Octagonal fuzzy Job sequencing problem is applicable in many real world situations. In many industrial engineering units, it is essential to economize the cost of production by saving idle time of machinery by utilizing them optimally. In order to find total elapsed time in job sequencing, Johnson`s method plays a vital role in solving job sequencing problems. Job sequencing is defined as finding the most appropriate order of performing jobs out of a number of operations to be performed that can be assigned to a number of facilities for optimum utilization.

\section{PRELIMINARIES}

In this part, usage of definition of a fuzzy set, crisp set, octagonal fuzzy number and its pictorial representations of octagonal fuzzy number, basic operations, new ranking method of fuzzy number definition and its properties are presented

\section{A. Definition:}

"A Fuzzy set A is defined as the set of ordered pairs ( $\mathrm{x}$, $\mu_{A}(x)$ ), where $x$ is an element of the universe of discourse $U$

\section{Revised Manuscript Received on February 14, 2020.}

* Correspondence Author

Althada Ramesh Babu*, Associate Professor, AS\&H Dept. Sasi Institute of Technology \& Engineering, Tadepalligudem, W G Dt. A.P. Pin: 534101- INDIA Email: rameshbabu.althada@sasi.ac.in

B. Rama Bhupala Reddy, Professor of Mathematics, KSRM College of Engineering, Kadapa, A.P. India, E-mail reddybrb@gmail.com

(C) The Authors. Published by Blue Eyes Intelligence Engineering and Sciences Publication (BEIESP). This is an open access article under the CC BY-NC-ND license (http://creativecommons.org/licenses/by-nc-nd/4.0/) and $\mu_{A}(x)$ is the membership function that attributes to each $\mathrm{X} \in \mathrm{U}$ a real number $\in[0,1]$ describing the degree to which $\mathrm{X}$ belongs to the set."

\section{B. Definition:}

"A crisp set is a special case of Fuzzy set, in which the membership function takes only two values 0 and 1."

\section{Definition:}

"An ordered number $\tilde{L}=\left(l_{1}, l_{2}, l_{3}, l_{4}, l_{5}, l_{6}, l_{7}, l_{8}\right)$ is to be an octagonal fuzzy number, where $l_{1}, l_{2}, l_{3}, l_{4}, l_{5}, l_{6}, l_{7}, l_{8}$ are real numbers from real line with its fuzzy membership function $\mu_{\tilde{L}}(x)$ is defined" [4]

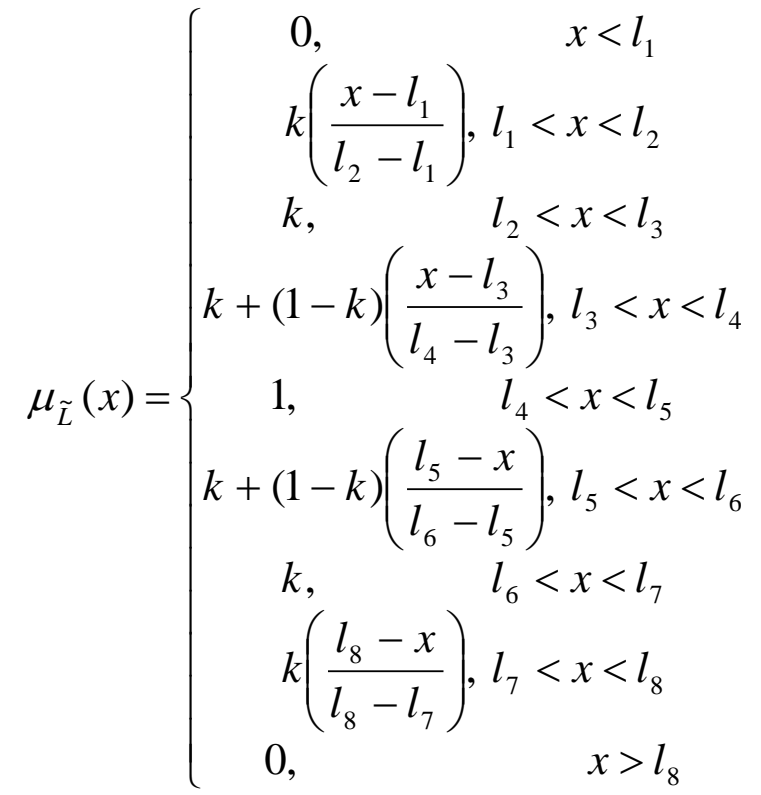

\section{Graphical representation of a octagonal fuzzy} number[4]

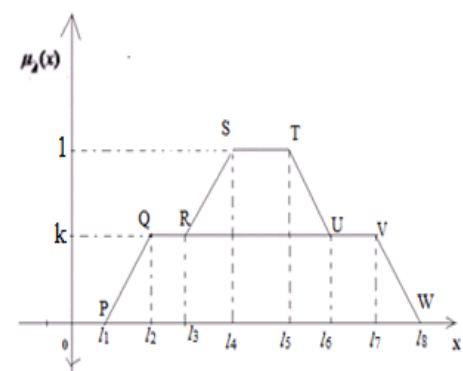

where $0<\mathrm{k}<1$

\section{E. Basic operations:}

"Let $\tilde{L}=\left(l_{1}, l_{2}, l_{3}, l_{4}, l_{5}, l_{6}, l_{7}, l_{8}\right)$ and $\tilde{M}=\left(m_{1}, m_{2}, m_{3}, m_{4}\right.$, $\left.m_{5}, m_{6}, m_{7}, m_{8}\right)$ be two octagonal fuzzy numbers, then its mathematical operations are defined as [4]

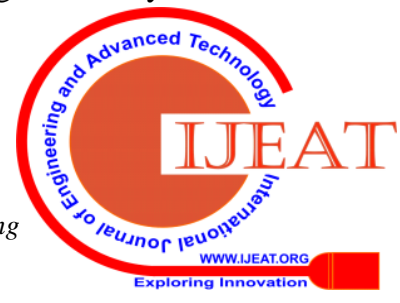


i: $\tilde{L} \oplus \tilde{M}=\left(l_{1}, l_{2}, l_{3}, l_{4}, l_{5}, l_{6}, l_{7}, l_{8}\right) \oplus\left(m_{1}, m_{2}, m_{3}, m_{4}, m_{5}\right.$, $\left.m_{6}, m_{7}, m_{8}\right)=\left(l_{1}+m_{1}, l_{2}+m_{2}, l_{3}+m_{3}, l_{4}+m_{4}, l_{5}+m_{5}, l_{6}+m_{6}\right.$, $\left.l_{7}+m_{7}, l_{8}+m_{8}\right)$

ii: $\tilde{L}-\tilde{M}=\left(l_{1}, l_{2}, l_{3}, l_{4}, l_{5}, l_{6}, l_{7}, l_{8}\right)-\left(m_{1}, m_{2}, m_{3}, m_{4}, m_{5}, m_{6}\right.$, $\left.m_{7}, m_{8}\right)=\left(l_{1}-m_{1}, l_{2}-m_{2}, l_{3}-m_{3}, l_{4}-m_{4}, l_{5}-m_{5}, l_{6}-m_{6}, l_{7}-m_{7}\right.$, $\left.l_{8}-m_{8}\right) "$

\section{F. Definition of ranking function:}

New method: The octagonal fuzzy number mentioned in the graph defined in 2.1.3 is divided into two plane figures. These two plane figures are PQVW and RSTU. Let the RU line on the QV. The balancing point for a generalized octagonal fuzzy number $\tilde{L}=\left(l_{1}, l_{2}, l_{3}, l_{4}, l_{5}, l_{6}, l_{7}, l_{8}\right)$ is

$$
\mathrm{R}(\tilde{L})=(1 / 6) *\left(\left(l_{1}+l_{8}\right)+\mathrm{k}\left(l_{2}+l_{3}+l_{6}+l_{7}\right)+\left(l_{4}+l_{5}\right)\right),
$$

\section{G. Properties}

An effective method of ordering the elements of $F(R)$ lies in defining a ranking of a function $R$ : $F(R) \rightarrow R$ which maps each fuzzy number into the real number and it is as given below: "if $\tilde{L}$ and $\tilde{M}$ are two octagonal fuzzy numbers then we have:

$$
\begin{aligned}
& \text { i. } \tilde{L} \leq \tilde{M} \Leftrightarrow R(\tilde{L}) \leq R(\tilde{M}) \\
& \text { ii. } \quad \tilde{L}=\tilde{M} \Leftrightarrow R(\tilde{L})=R(\tilde{M}) \& \\
& \text { iii. } \quad \tilde{L} \geq \tilde{M} \Leftrightarrow R(\tilde{L}) \geq R(\tilde{M}),
\end{aligned}
$$

\section{PROCESS}

The process for solving Octagonal Fuzzy Sequencing Problem of $n$ jobs through two machines:

Step:I First convert octagonal fuzzy sequencing problem into crisp problem using New method mentioned in II.F.

Step:2 Later apply job sequence rule to the above crisp problem and then calculate idle/elapsed time using the below procedure.

The process is explained as shown below:

a) The two machines are $\mathrm{A}$ and $\mathrm{B}$

b) Each job is processed in the order of $A$ and $B$.

c) The processing times of jobs $\mathrm{A}$ and $\mathrm{B}$ are shown in the Table -I

Table- I: [5]

\begin{tabular}{|c|c|c|c|c|c|c|c|c|}
\hline \multirow{2}{*}{ Machine } & \multicolumn{7}{|c|}{ Job(s) } & \\
\cline { 2 - 9 } & 1 & 2 & 3 & - & - & $\mathrm{i}$ & - & $\mathrm{N}$ \\
\hline $\mathrm{A}$ & $\mathrm{A}_{1}$ & $\mathrm{~A}_{2}$ & $\mathrm{~A}_{3}$ & -- & - & $\mathrm{A}_{\mathrm{i}}$ & -- & $\mathrm{A}_{\mathrm{n}}$ \\
\hline $\mathrm{B}$ & $\mathrm{B}_{1}$ & $\mathrm{~B}_{2}$ & $\mathrm{~B}_{3}$ & -- & - & $\mathrm{B}_{\mathrm{i}}$ & -- & $\mathrm{B}_{\mathrm{n}}$ \\
\hline
\end{tabular}

The problem is to find the sequence (or order) of jobs so as to minimize the total elapsed time

The solution of the above problem is also known as Johnson`s procedure which involves the following step:

Step:3 Select the smallest processing time occurring in the list $A_{1}, A_{2}, A_{3},---, A_{n} ; B_{1}, B_{2}, B_{3},---, B_{n}$ if there is a tie, either of the smallest processing times can be selected.

Step:4 If the least processing time is $A_{r}$, select the $r^{\text {th }}$ job first. If it is $B_{s}$, do the $s^{\text {th }}$ job last as the given order is $A B$
Step:5 There are now $n-1$ jobs left to be kept in the order. Repeat the steps I \& II .

Step:6 Continue in the same manner till all the jobs have been sequenced. The resulting ordering of jobs leads to minimization of elapsed time $\mathrm{T}$ and it is called the optimal sequence.

Step:7 After completing the above, find the optimal

\begin{tabular}{|c|c|}
\hline $\begin{array}{l}\text { Total } \\
\text { elapsed } \\
\text { time } \\
=\end{array}$ & $\begin{array}{l}\text { The time between starting the first job in the optimal } \\
\text { sequence on machine A and completing the last job in the } \\
\text { optimal machine B. }\end{array}$ \\
\hline $\begin{array}{l}\text { Idle } \\
\text { time on } \\
\text { machine } \\
\mathrm{A}=\end{array}$ & $\begin{array}{l}\text { (Time when the last job in the optimal sequence on } \\
\text { sequences is completed on machine B)- (Time when the } \\
\text { last job in the optimal sequences is completed on machine } \\
\text { A) }\end{array}$ \\
\hline $\begin{array}{l}\text { Idle } \\
\text { time on } \\
\text { machine } \\
\mathrm{B}=\end{array}$ & $\begin{array}{l}\text { (Time when the first job in the optimal sequences is } \\
\text { completed } \text { on }{ }^{\text {th }} \text { machine } \\
\sum_{k=2}^{n}\left[\left(\text { time when } k^{\text {th }} \text { job starts on machine } B\right)-\right. \\
\left.\left(\text { time }(k-1)^{\text {th }} \text { job finished on machine } B\right)\right]\end{array}$ \\
\hline
\end{tabular}
sequence and also idle and total elapsed time. It is shown as under:

\section{Table- II:}

The Johnson's procedure can be illustrated by following examples:

\section{NUMERICAL EXAMPLE}

This example is taken from the paper "Fuzzy Sequencing Problem: A Noval Approach” by M. Shanmuga sundari [6].

\section{A. Example :}

The fuzzy sequencing problem with nine jobs through two machines has been considered where the order is AB. Here, processing time of each machine for each job in Octagonal

\begin{tabular}{|c|c|c|c|}
\hline \multicolumn{2}{|c|}{ TASK } & MACHINE - A & MACHINE - B \\
\hline \multirow[b]{3}{*}{$\mathrm{J}$} & I & $(0,0.2,1,2,3,3.5,4,5)$ & $(15,16.3,17,18,20,20.5,21,22$ \\
\hline & II & $\begin{array}{c}(9,10,11,12,14,14.5,15,16 \\
)\end{array}$ & $\begin{array}{c}(9.5,10.4,11.2,12,13,13.5,14, \\
15)\end{array}$ \\
\hline & III & $(7.2,8,9,10,12,12.5,13,14)$ & $\begin{array}{c}(14.6,15.5,16,17,20,20.5,21, \\
22)\end{array}$ \\
\hline $\mathrm{O}$ & IV & $\begin{array}{c}(17.9,18.7,19.1,20,22,22 . \\
5,23,24)\end{array}$ & $(7.2,8,9,10,12,12.5,13,14)$ \\
\hline B & V & $\begin{array}{c}(15,16.3,17,18,20,20.5,21 \\
, 22)\end{array}$ & $(5,6.3,7,8,10,10.5,11,12)$ \\
\hline \multirow[t]{4}{*}{$\mathrm{S}$} & VI & $\begin{array}{r}(9.5,10.4,11.2,12,13,13.5 \\
14,15)\end{array}$ & $\begin{array}{c}(17.9,18.7,19.1,20,22,22.5,2 \\
3,24)\end{array}$ \\
\hline & VII & $\begin{array}{c}(14.6,15.5,16,17,20,20.5, \\
21,22)\end{array}$ & $(5,6.3,7,8,10,10.5,11,12)$ \\
\hline & $\begin{array}{c}\text { VII } \\
\text { I }\end{array}$ & $\begin{array}{c}(9,10,11,12,14,14.5,15,16 \\
)\end{array}$ & $\begin{array}{c}(17.9,18.7,19.1,20,22,22.5,2 \\
3,24)\end{array}$ \\
\hline & IX & $(7.2,8,9,10,12,12.5,13,14)$ & $(22,23,24,25,28,28.5,29,30)$ \\
\hline
\end{tabular}
Fuzzy Number.

Table- III: Consider the following sequencing problem given

This is taken from[7]

Solution: 
Table- IV: The above problem is converted into crisp problem using new method for taking $k=0.5$.

\begin{tabular}{|c|c|c|c|c|c|}
\hline & I & II & III & IV & V \\
\hline A & 2.391667 & 12.70833 & 10.74167 & 20.925 & 18.7333 \\
\hline B & 18.48333 & 12.09167 & 18.1 & 10.49167 & 8.48333 \\
\hline & VI & VII & VIII & IX & \multirow{2}{*}{1} \\
\cline { 1 - 5 } A & 12.34167 & 18.35 & 12.70833 & 10.74167 & \multirow{2}{*}{} \\
\cline { 1 - 5 } B & 20.675 & 8.483333 & 20.675 & 25.95833 & \\
\hline
\end{tabular}

Table- V: This crisp problem is used to find the priority of job sequence i.e Fuzzy optimal sequence using Johnson`s rule

\begin{tabular}{|l|l|l|l|l|l|l|l|l|}
\hline \multicolumn{1}{|c|}{ rule } \\
\hline 1 & 3 & 9 & 6 & 8 & 2 & 4 & 7 & 5 \\
\hline
\end{tabular}

Table- VI: Calculation of Idle times:

\begin{tabular}{|c|c|c|c|c|}
\hline & \multicolumn{2}{|c|}{ MACHINE - A } & \multicolumn{2}{|c|}{ MACHINE - B } \\
\hline JOB & TIME IN & TIME OUT & TIME IN & TIME OUT \\
\hline 1 & $\begin{array}{c}(0,0,0,0,0,0 \\
0,0)\end{array}$ & $\begin{array}{c}(0,0.2,1,2,3,3 \\
.5,4,5)\end{array}$ & $\begin{array}{c}(0,0.2,1,2,3,3 . \\
5,4,5)\end{array}$ & $\begin{array}{c}(15,16.5,18, \\
20,23,24,25 \\
, 27)\end{array}$ \\
\hline 3 & $\begin{array}{c}(0,0.2,1,2,3 \\
3.5,4,5)\end{array}$ & $\begin{array}{c}(7.2,8.2,10,1 \\
2,15,16,17,1 \\
9) \\
\end{array}$ & $\begin{array}{c}(15,16.5,18,20 \\
, 23,24,25,27)\end{array}$ & $\begin{array}{c}(29.6,32,34, \\
37,43,44.5, \\
46,49)\end{array}$ \\
\hline 9 & $\begin{array}{c}(7.2,8.2,10 \\
12,15,16,17 \\
, 19)\end{array}$ & $\begin{array}{c}(14.4,16.2,19 \\
, 22,27,28.5,3 \\
0,33)\end{array}$ & $\begin{array}{c}(29.6,32,34,37 \\
\text {,43,44.5,46,49 } \\
)\end{array}$ & $\begin{array}{c}(51.6,55,58, \\
62,71,73,75 \\
, 79)\end{array}$ \\
\hline 6 & $\begin{array}{c}(14.4,16.2,1 \\
9,22,27,28 . \\
5,30,33) \\
\end{array}$ & $\begin{array}{c}(23.9,26.6,30 \\
.2,34,40,42,4 \\
4,48) \\
\end{array}$ & $\begin{array}{c}(51.6,55,58,62 \\
, 71,73,75,79)\end{array}$ & $\begin{array}{r}(69.5,73.7,7 \\
7.1,82,93,9 \\
5.5,98,103) \\
\end{array}$ \\
\hline 8 & $\begin{array}{c}(23.9,26.6,3 \\
0.2,34,40,4 \\
2,44,48)\end{array}$ & $\begin{array}{c}(32.9,36.6,41 \\
.2,46,54,56.5 \\
, 59,64)\end{array}$ & $\begin{array}{c}(69.5,73.7,77 \\
1,82,93,95.5,9 \\
8,103)\end{array}$ & $\begin{array}{c}(87.4,92.4,9 \\
6.2,102,115 \\
, 118,121,12 \\
7)\end{array}$ \\
\hline 2 & $\begin{array}{c}(32.9,36.6,4 \\
1.2,46,54,5 \\
6.5,59,64)\end{array}$ & $\begin{array}{c}(41.9,46.6,52 \\
.2,58,68,71,7 \\
4,80)\end{array}$ & $\begin{array}{c}(87.4,92.4,96 . \\
2,102,115,118 \\
, 121,127)\end{array}$ & $\begin{array}{c}(96.9,102.8, \\
107.4,114,1 \\
28,131.5,13 \\
5,142)\end{array}$ \\
\hline 4 & $\begin{array}{c}(41.9,46.6,5 \\
2.2,58,68,7 \\
1,74,80)\end{array}$ & $\begin{array}{c}(59.8,65.3,71 \\
.3,78,90,93.5 \\
, 97,104)\end{array}$ & $\begin{array}{c}(96.9,102.8,10 \\
7.4,114,128,1 \\
31.5,135,142)\end{array}$ & $\begin{array}{c}(104.1,110 . \\
8,116.4,124 \\
, 140,144,14 \\
8,156) \\
\end{array}$ \\
\hline 7 & $\begin{array}{c}(59.8,65.3,7 \\
1.3,78,90,9 \\
3.5,97,104)\end{array}$ & $\begin{array}{c}(74.4,80.8,87 \\
.3,95,110,11 \\
4,118,126)\end{array}$ & $\begin{array}{c}(104.1,110.8,1 \\
16.4,124,140 \\
144,148,156)\end{array}$ & $\begin{array}{c}(109.1,117 . \\
1,123.4,132 \\
, 150,154.5 \\
159,168)\end{array}$ \\
\hline 5 & $\begin{array}{c}(74.4,80.8,8 \\
7.3,95,110, \\
114,118,12 \\
6) \\
\end{array}$ & $\begin{array}{c}(89.4,97.1,10 \\
4.3,113,130, \\
134.5,139,14 \\
8)\end{array}$ & $\begin{array}{c}(109.1,117.1,1 \\
23.4,132,150 \\
154.5,159,168 \\
)\end{array}$ & $\begin{array}{c}114.1,123 . \\
4,130.4,140 \\
, 160,165,17 \\
0,180)\end{array}$ \\
\hline
\end{tabular}

Idle Time for $\mathrm{A}=(114.1,123.4,130.4,140,160,165,170,180)$ -

$$
(89.4,97.1,104.3,113,130,134.5,139,148)
$$

$$
=(24.7,26.3,26.1,27,30,30.5,31,32) \text { hours }
$$

$\mathrm{R}(\mathrm{A})=28.447$ hours

Idle Time for $\mathrm{B}=(0,0.2,1,2,3,3.5,4,5)$ hours

$\mathrm{R}(\mathrm{B})=2.3916$ hours

Total elapsed time $=$

$(114.1,123.4,130.4,140,160,165,170,180)$ hrs

$\mathrm{R}($ Total elapsed time $)=145.5833$ hours

\section{RESULTS}

We applied problem mentioned in Table-III using new method we get a better result on compared with robust method mentioned in [7]

Table-VII

\begin{tabular}{|l|c|c|c|}
\hline & $\begin{array}{l}\text { IDLE TIME } \\
\text { FOR A }\end{array}$ & $\begin{array}{l}\text { IDLE TIME } \\
\text { FOR B }\end{array}$ & $\begin{array}{l}\text { TOTAL ELAPSED } \\
\text { TIME }\end{array}$ \\
\hline $\begin{array}{l}\text { ROBUST } \\
\text { METHOD[7] }\end{array}$ & 28.605 & 2.3525 & 148.2575 \\
\hline NEW METHOD & 28.447 & 2.3926 & $\mathbf{1 4 5 . 5 8 3 3}$ \\
\hline
\end{tabular}

\section{CONCLUSION}

Hence, the present paper has attempted to present a new ranking method called Octagonal number fuzzy sequencing problem. It has presented the elapsed time and idle time. It is proved that that the new method has led to finding the best result. On compare with robust method

\section{REFERENCES}

1. Bellman.R.E, Zadeh.L.A, "Decision making in fuzzy environment, Management Sciences" 17 (1970), 141-164.

2. Fang.S.C, Hu.C.F, Wang.H.F, Wu.S.Y, "Linear programming with fuzzy coefficient in constraints, Computers \& Mathematics with applications" 37 (1999), 63-76.

3. Zadeh.A, Fuzzy sets, "Information \& Control" 8 (1965), 338-353

4. Althada Ramesh Babu. "An Alternative Solution for a Fuzzy Octagonal Number Transportation Problem”, Compliance Engineering Journal Volume 10, Issue 9, 2019, 239-245.

5. S.D.Sharma, "Operations Research" Kedarnath Ram Nath \& Co. Publishers Meerut. $13^{\text {th }}$ Edition Page No 924 -926.

6. Shanmugasundari .M. "Fuzzy Sequencing Problem: A Novel Approach", International Journal of Pure and Applied Mathematics, Volume 113, No.13 2017, 56 - 64.

7. Dr.S.U. Malini. "Solving Fuzzy Sequencing problem using Octogonal Fuzzy number", International Journal of Mathematical Archive - 9(9), 2018,109-114.

\section{AUTHORS PROFILE}

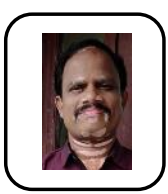

A.Ramesh Babu, Research Scholar, Department of Mathematics, JNTUA, Ananthapuram. India. Published 4 international journals in the area of Fuzzy linear programming. He is working as an Associate Professor in Department of Applied Sceinces and Humanities, Sasi Institute o Technology Engineering, Tadepalligudem, A.P.

India.

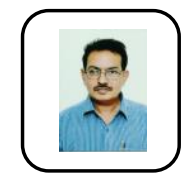

Dr. B. Rama Bhupal Reddy, published 95 papers in national international journals, published 12 books in Mathematics, and he is currently the Chairman of Board of Studies. Head and Professor, Department of Mathematics, K.S.R.M. College of Engineering (Autonomous), Kadapa, A.P. India, Member of PG Board of Studies, JNTUA, Ananthapuram, India. Member of Board of Studies Mathematics, Sasi Institute of Technology \& Engineering, Tadepalligudem, A.P. India. He has Brilliant Academic career all through teaching experience at Under graduate and Post graduate. His research interests include Computational Fluid Dynamics and Mathematical Modelling. He has supervised 15 M.Phil., students and guided one Ph.D. student.. 